\title{
RAZONAMIENTO LÓGICO-MATEMÁTICO EN LAS ESCUELAS
}

\author{
Licda. Rocio Berrocal Mora* \\ Lic. Oscar Gómez Berrocal**
}

Fundamentados en el desarrollo de su tesis de licenciatura Estrategia metodológica para el desarrollo del razonamiento lógicomatemático, presentado ante la División áe Educación Rural del CIDE, los autores explican las seis etapas propuestas por el matemático alemán Zoltan Pier Dienes y proponen una alternativa para profundizar y lograr un mejor rendimiento en el desarrollo del pensamiento fáctico.

El lector encontrará una propuesta metodológica, amparada en los presupuestos teóricos del presente artículo, en el suplemento EDUCARE en el aula en esta edición.
Basedon the results of their licenciatura thesis, "Methodological strategy for the development of logical-mathematical reasoning, " presented to the Division of Rural Education, CIDE, the authors explain the six phases developed by the German mathematician, Zotan Pier Dienes. They propose an alternative strategy to deepen and accomplish abetter achievement in the development offactual thinking.

The reader will find, in the section "EDUCARE in the classroom" that appears in this edition, a methodological proposal, founded in the theoretical postulates presented and discussed in this article.

* Licenciada en Ciencias de la Educación con énfasis en I y II Ciclo por la División de Educación Rural del Centro de Investigación y Docencia en Educación de la Universidad Nacional. Profesora en la Escuela Once de Abril ubicada en La Guácima, Alajuela.

** Licenciado en Ciencias de la Educación con énfasis en I y II Ciclo por a División de Educación Rural del Centro de Investigación y Docencia en Educación de la Universidad Nacional. Profesor en la Escuela Rincón Herrera ubicada en La Guácima, Alajuela. 
Es primordial programar y llevar a la práctica procesos de aprendizaje que faciliten, en una forma lúdica, el desarrollo del razonamiento lógico. El juego dirigido es una alternativa fundamental e interesante
Tradicionalmente en el aula se ha puesto demasiado énfasis en el trabajo sobre problemas y ejercicios rutinarios, al abordar cada uno de los temas en el área de la Matemática. Los estudiantes están acostumbrados a que sean solamente los docentes quienes propongan las situaciones a

resolver y que éstas tengan sólo una solución correcta.

Este sistema de enseñanza y aprendizaje, en donde los estudiantes son receptores de datos, ha traído consecuencias negativas, como el bajo rendimiento académico, e inclusive fobia hacia la matemática. $\mathrm{Al}$ respecto, la asesora de matemática, Ulate, (23/7/1999, La Nación, p. 20-A) afirma que "el problema del bajo rendimiento académico en el área de la Matemática, radica en las malas bases y principalmente, la falta de estrategias que conlleven al desarrollo del pensamiento lógico-matemático."

Por lo tanto, es primordial programar y llevar a la práctica procesos de aprendizaje que faciliten, en una forma lúdica, el desarrollo del razonamiento lógico. El juego dirigido es una alternativa fundamental e interesante para crear situaciones que le permitan a niños y niñas descubrir relaciones que favorezcan la construcción del conocimiento. Según Abarca (1990, p. 47), "los docentes deben ayudar a los estudiantes a ser creativos, a innovar, a encarar emergencias e imprevistos", lo que no ocurre sin una previa planificación que facilite la construcción del conocimiento.

Para desarrollar procesos constructivos, es indispensable utilizar estrategias de juego, para que el aprendizaje de los niños sea más significativo, es decir, en concordancia con sus necesidades, intereses y vivencias. Es importante que la enseñanza de la matemática esté llena de situaciones y retos interesantes, que despierten el interés y la motivación en la realización de las tareas escolares. Esto implica un mayor desempeño y una actitud más positiva hacia la materia mencionada.

Artavia 2000, en el Segundo Festival de Matemática organizado por el CIENTEC, con Sede en la Universidad Nacional, afirma que "los estudiantes llegan a pensar que la Matemática es una colección de definiciones y reglas que hay que memorizar". Sin embargo, la enseñanza de la matemática implica aspectos lógico-verbales, (uso de símbolos abstractos, el lenguaje formalizado, el cálculo, la lógica formal, los procedimientos analíticos) y aspectos visualimaginativos (dominio de las imágenes visuales, los aspectos intuitivos, la 
capacidad para detectar formas). Estos aspectos no conviene darlos en forma excluyente, se deben proponer metodologías más activas, que permitan integrar ambos componentes, para producir una imagen más realista de la naturaleza de esa asignatura.

El matemático alemán Dienes (1981), sostiene lo siguiente:

"Existen diferentes etapas que, naturalmente, habrá que tener en cuenta en la organización del proceso de enseñanza de la Matemática, si se pretende que todos los niños accedan a ella."(p. 8)

Propone entonces el autor, seis etapas por medio de las cuales los escolares aprenderán los conceptos matemáticos.

\section{Primera etapa: (Juego librè)}

Consiste en la utilización de material concreto, que los estudiantes eligen o que es facilitado por un docente. Este material es manipulado por los niños para crear su propio juego. Ese mismo material podrá ser utilizado en las etapas posteriores.

Segunda etapa: (Juego estructurado)

También se le llama etapa de la consigna, en la cual el docente da los pasos a seguir para que los estudiantes los ejecuten utilizando el material empleado en la etapa anterior.

Tercera etapa: (Isomorfismo)

En esta etapa se le presenta un juego diferente a los alumnos, pero con la misma estructura del anterior, para que encuentren las semejanzas y diferencias entre ambos.

Cuarta etapa: (Representación gráfica)

Consiste en representar gráficamente las actividades realizadas en las etapas anteriores, sobre todo las relacionadas con la etapa del "juego estructurado". 


\section{Quinta etapa: (Verbalización)}

Es la descripción verbal, por parte de los estudiantes, de las representaciones gráficas realizadas; utilizando un lenguaje inventado por ellos mismos.

Sexta etapa: (Juego de la demostración)

En la última, los estudiantes logran convertir las descripciones en teoremas del sistema, por medio de la puesta en práctica de nociones vividas en las etapas concretas y semiconcretas.

Las estrategias propuestas en el suplemento de esta revista, están basadas en los estudios ya descritos, en los cuales se guía, tanto a docentes como a estudiantes, para evolucionar de una etapa a otra, por medio de una serie de juegos estructurados con actividades concretas y semiconcretas; que sirven de base para lograr un mayor nivel de abstracción.

Cada actividad induce al análisis para descubrir diferentes maneras de resolver una misma situación problemática determinada. Están organizadas en un orden de menor a mayor dificultad. Los docentes pueden adecuarlas a cualquier nivel de la Enseñanza General Básica. Desde preescolar hasta II Ciclo es urgente fomentar este tipo de actividades, si se desea cambiar el panorama de los viejos esquemas que obstaculizan los procesos de aprendizaje, coaccionando la capacidad de análisis y razonamiento de los estudiantes.

En la actualidad, el objetivo principal es abrir la brecha para que los estudiantes sean capaces de enfrentar los nuevos retos que exige el mundo moderno.

\section{Referencias}

Abarca, S. (1990). Psicología de la educación. Alajuela: MEP-CIPET.

Artavia, E. (2000). Seminario integrativo de matematica. II Festival. Heredia: UNA-CIENTEC.

Dienes. Z. P. (1986). Las seis etapas del aprendizaje en matemática. Barcelona: Teide.

Ulate, M. (199, lulio 23). Causas del bajo rendimiento académico en matemática. La Nación p. $20 \mathrm{~A}$. 